\title{
Method of alkaline destruction as the way to stop methanogenic effluent's gasification
}

\author{
Roman Tarasenko $^{1}$., Lydmila Starzhinsca ${ }^{2}$., Yevhenii Poluncin ${ }^{2}$., Yevhenii Shapovalov ${ }^{3}$ \\ ${ }^{1}$ Junior Academy of Science of Ukraine, Ukraine, Kiev, Degtyarivska 38/44, E-mail:gws0930191302@ gmail.com,, : \\ sjb@man.com.ua \\ ${ }^{2}$ Institute of Bioorganic Chemistry and Petrochemistry named V.P Kuhar of the National Academy of Sciences of \\ Ukraine, Ukraine, Kiev, Murmanskaya 1, E-mail:polunkin@i.ua, starlydmila@ukr.net
}

\section{Abstract - We propose using a method of alkaline destruction to solve the problem of effluent's gasification. It can provide production synthesis gas and humate.}

Keywords - alkaline destructions, humate, fertilizer gasification, NMR spectroscopy, effluent.

One of the main problems which limit the distribution of biogas plants is the fertilizer gasification [1]. This process provides a problem of the fertilizer storage. Previously additional fermentation was conducted to solve this problem. It is characterized by additional biogas output, but it suppose to build additional biogas reactor and this it still does not supply completed fermentation [2]. We propose the process of alkaline destructions to solve this problem. It can provide production synthesis gas and humate.

The cylindrical stainless steel reactor with a volume of 41 was used to the research of chicken manure alkaline destruction. The process was carried out at a temperature of $200{ }^{\circ} \mathrm{C}$ during $3 \mathrm{~h}$. Reactions mixture consists of $1 \mathrm{~kg}$ dried effluent $0,3 \mathrm{~kg}$ effluents liquid phase $0,3 \mathrm{~kg}$ potassium hydroxide. The effluent was obtained by anaerobic digestion with HRT time of 10 days in thermophilic condition $\left(50{ }^{\circ} \mathrm{C}\right)$ [1] and after that was detached from the liquid phase. The method of one-dimensional NMR spectroscopy on 1H 31P nuclei was used foraffiliation of obtained product to humates and determine their quantit Samples of produced compounds were prepared using the standard method of NMR-spectroscopy sample preparation (GOST R 8.620-2006). The quantity of free humic acids was analyzed by method sedimentation using concentrated hydrochloric acid (GOST R 54221-2010).

The obtained product was characterized by absent microbiological activity which is related to the aim of work. NMR spectra of obtained product were appropriate to the peak of NMR spectra of natural humic acids of fertile soil (fig.).

a)

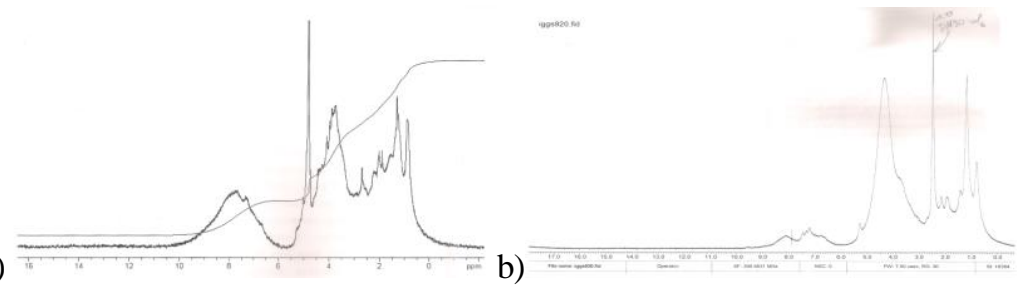

Fig. NMR-spectra of humic acids a) of natural humic acids of fertile soil b) of sample produced under alkalinity destruction of chicken manure

The content of free humic acids was $1,01 \%$ of dry matter. This content corresponds to optimal humates concentration in the fertilizers which are in the range of 1 to $2 \%$ [3]. It means that achieved fertilizer is more attractive to achieve better quality and quantity of plant

Therefore, the method of alkaline destruction is assembled to solve the problem of effluent excess gasification of methanogenic effluent's. In addition, this approach can increase the economic attractiveness of anaerobic digestion due to the simplicity of the proposed installation and obtaining of humates.

\section{References}

[1] A.I. Salyuk, "International Scientific Journal for Alternative Energy and Ecology (ISRAEL)”.,No 4, pp 89-98, 2017.

[2] Zhan-Guand Lui “Waste management”., No 32, pp. 137-147, 2012.

[3] Richard T. Lamar “JournaL of AOAC International”., No 3, pp. 721-730, 2014. 